\title{
A reproducible reference point for the common peroneal nerve during surgery at the posterolateral corner of the knee: a cadaveric study
}

Hong Lee Terry Teo, Ke Xin Magneline Ang ${ }^{*}$ and Sir Young James Loh

\begin{abstract}
Background: This is an experimental study conducted to assess whether the fibular head is a reliable reference point to identify the position of the common peroneal nerve at the posterolateral corner of the knee.

Materials and methods: Twelve cadaveric knees were dissected through the lateral approach. The common peroneal nerve was identified and traced. The location where the common peroneal nerve crossed the posterior border of the biceps femoris and the posterior border of the fibular neck were designated as points $\mathrm{B}$ and $\mathrm{N}$, respectively. The tip of the fibular head was designated F. Distances FB and FN were measured and the triangular area FBN was calculated at various degrees of knee flexion.

Results: During knee motion, distance FN showed minimal change and was not affected by variation in degrees of knee flexion $(p=0.131)$. Distance FB and distance BN were affected by variation in degrees of knee flexion $(p<0.001)$. Triangular area FBN increased in size up to $60^{\circ}$ of knee flexion measuring $621.22 \mathrm{~mm}^{2}$ and subsequently decreased with further knee flexion.

Conclusion: The common peroneal nerve can consistently be found at approximately $20.7 \pm 1 \mathrm{~mm}$ on the fibular neck with respect to the tip of the fibular head. The tip of the fibular head is a consistent landmark that can be used to predict the position of the exit point of the common peroneal nerve at the posterolateral corner of the knee.
\end{abstract}

Keywords: Common peroneal nerve injury, Posterolateral corner, Reference point, Fibular head, Fibular neck, Biceps femoris

\section{Introduction}

The common peroneal nerve $(\mathrm{CPN})$ is the main neurological structure present at the posterolateral corner (PLC) of the knee joint and it is the most important structure passing through this location. It is one of the two nerves arising from the bifurcation of the sciatic nerve in the posterior aspect of the thigh and is supplied by branches of L4-S2 spinal nerve roots. It travels along the biceps femoris and around the neck of the fibula,

\footnotetext{
* Correspondence: magneline.ang@mohh.com.sg Department of Orthopaedic Surgery, Changi General Hospital, Singapore, Singapore
}

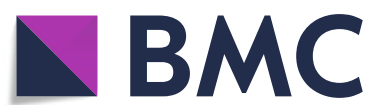

Part of Springer Nature and splits into the superficial and deep peroneal nerves. It innervates the muscles of the anterior and lateral compartments of the leg, which play an important role in gait. The purpose of this experimental study is to assess whether the fibular head is a reliable reference point to identify the position of the CPN at the PLC of the knee.

The CPN is particularly susceptible to injury because of its fixed attachment in the region of the neck of the fibula. In PLC injuries $[1,2]$ when the knee is subjected to varus and hyperextension forces, there may be traction injury of the CPN alongside alteration of the anatomy of the PLC. Recovery is generally considered to be

(c) The Author(s). 2020 Open Access This article is licensed under a Creative Commons Attribution 4.0 International License, which permits use, sharing, adaptation, distribution and reproduction in any medium or format, as long as you give appropriate credit to the original author(s) and the source, provide a link to the Creative Commons licence, and indicate if changes were made. The images or other third party material in this article are included in the article's Creative Commons licence, unless indicated otherwise in a credit line to the material. If material is not included in the article's Creative Commons licence and your intended use is not permitted by statutory regulation or exceeds the permitted use, you will need to obtain permission directly from the copyright holder. To view a copy of this licence, visit http://creativecommons.org/licenses/by/4.0/ The Creative Commons Public Domain Dedication waiver (http://creativecommons.org/publicdomain/zero/1.0/) applies to the data made available in this article, unless otherwise stated in a credit line to the data. 
poor $[3,4]$. CPN neuropraxia has been reported due to hematoma formation at the fibular head after primary injury [5] and may also be a concern should a postoperative hematoma lead to nerve compression.

During surgeries at the PLC, the CPN is potentially at risk and the devastating consequences of injury to this structure cannot be over emphasised. CPN neurolysis is typically performed during procedures for PLC to minimise the risk of foot drop post-operatively due to swelling. Risk of CPN palsy post-operatively can be as high as $2.5 \%$ from various large retrospective meta-analyses performed [1]. Such a risk can be controlled with an easily reproducible and relatively precise guide to the relation of the nerve with surrounding identifiable landmarks. The authors hypothesise that the tip of the fibular head is a reliable reference point to predict the position of the $\mathrm{CPN}$ for use during surgery at the PLC.

\section{Materials and methods}

\section{Specimens}

This is a cadaveric study to assess the position of the CPN in relation to a reliable landmark at the PLC of the knee. It was performed under the funding of a local hospital grant (IO no. 12200257).

Twelve knee specimens from nine Caucasian cadavers were procured for this study. These consist of four male and five female cadavers with a contribution of six knee specimens from each gender. All the cadavers are from individuals who died from non-traumatic causes, aged 59 to 95 years old (mean 80.25 years). They had a height of $152.2-182.9 \mathrm{~cm}$ (mean $167.9 \mathrm{~cm}$ ) and weighed $56.7-$ $78.1 \mathrm{~kg}$ (mean $67.4 \mathrm{~kg}$ ). The specimen data is provided in Table 1.

The knee specimens were carefully examined and tested manually for any sign of injuries or instability. The specimens were all stored at $-20^{\circ} \mathrm{C}$ and defrosted 12 to $14 \mathrm{~h}$ prior to examination and dissection.

\section{Surgical technique for anatomical examination}

The study constituted careful and detailed dissection of cadaveric knee specimens. Dissection was initiated via a curvilinear incision on the lateral knee specimen in $90^{\circ}$ of flexion. This involved starting $50 \mathrm{~mm}$ proximal to the lateral epicondyle and curving the incision distal to the lateral epicondyle. The incision passed between Gerdy's tubercle and the fibular head. It concluded approximately $30 \mathrm{~mm}$ distal to the level of the fibular neck. Incision lengths were measured using a standard $15-\mathrm{cm}$ ruler. The subcutaneous dissection was performed to the iliotibial band, then the distal biceps femoris and fibular neck were adequately exposed.

The CPN was next exposed only enough to identify its path. The point that it crossed the posterior border of the biceps femoris was designated $\mathrm{B}$ and the point that it penetrated the fascia at the level of the fibular neck was designated $\mathrm{N}$. The attachments of the nerve at points $\mathrm{B}$ and $\mathrm{N}$, as well as the soft tissue between these two points were carefully preserved. The tip of the fibular head was designated F. This was identified via a longitudinal incision over the palpable structure, adequate to

Table 1 Basic characteristics of specimens: anthropometric measurements of cadavers

\begin{tabular}{|c|c|c|c|c|c|c|}
\hline No. & Laterality & Age (years) & Sex & Height $(\mathrm{cm})$ & Weight (kg) & Body Mass Index \\
\hline 1 & Left & 88 & Female & 152.4 & 68.2 & 29 \\
\hline 2 & Left & 59 & Female & 167.6 & 78.1 & 28 \\
\hline 3 & Right & 59 & Female & 167.6 & 78.1 & 28 \\
\hline 4 & Left & 85 & Male & 182.9 & 64.4 & 19 \\
\hline 5 & Left & 73 & Female & 167.6 & 66.7 & 24 \\
\hline 6 & Right & 85 & Male & 182.9 & 64.4 & 19 \\
\hline 7 & Left & 89 & Male & 162.6 & 64.0 & 22.8 \\
\hline 8 & Left & 73 & Male & 175.3 & 61.2 & 19.9 \\
\hline 9 & Left & 95 & Female & 160.0 & 71.2 & 27.8 \\
\hline 10 & Right & 89 & Male & 162.6 & 64.0 & 22.8 \\
\hline 11 & Right & 92 & Male & 177.8 & 71.2 & 22.5 \\
\hline 12 & Right & 76 & Female & 154.9 & 56.7 & 23.6 \\
\hline Mean & - & 80.25 & - & 167.9 & 67.4 & 23.9 \\
\hline Standard deviation & - & 12.21 & - & 10.13 & 6.42 & 3.61 \\
\hline Variance & - & 149.11 & - & 102.59 & 41.2 & 13.02 \\
\hline Skewness & - & -0.79 & - & 0.16 & 0.43 & 0.10 \\
\hline Kurtosis & - & -0.52 & - & -0.97 & -0.15 & -1.35 \\
\hline
\end{tabular}




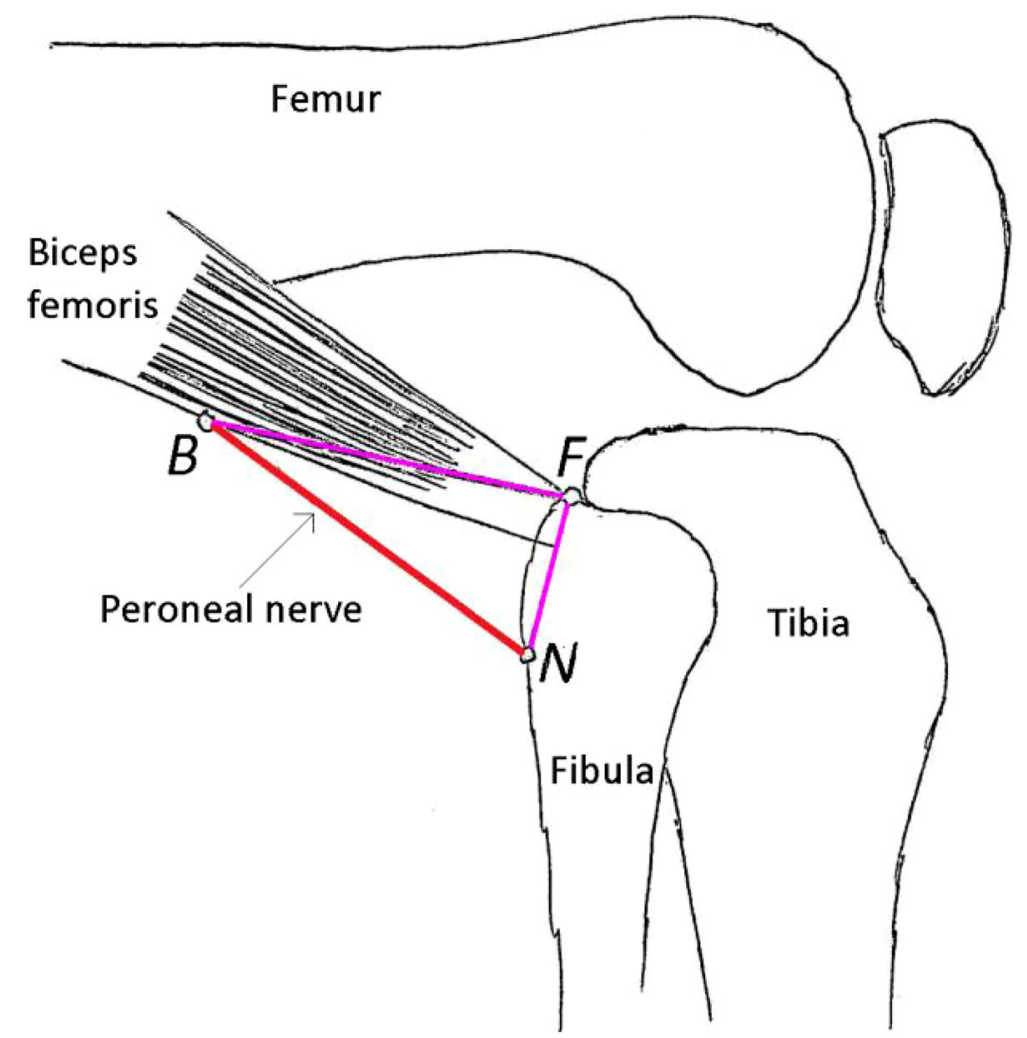

Illustration 1 Schematic diagram: showing the tip of the fibular head $(F)$, the posterior border of the biceps femoris where the common peroneal nerve (CPN) crosses (B) and the posterior border of the fibular neck where the CPN crosses (N)

identify it. Illustration 1 shows a schematic diagram of the PLC. Figure 1 is a picture of one of the specimens after dissection. The distance between the point that the $\mathrm{CPN}$ crosses the posterior border of the biceps femoris (B) and the tip of the fibular head (F) was designated FB.
The distance between the point that the CPN enters the fascia at the level of the fibular neck $(\mathrm{N})$ and the tip of the fibular head (F) was designated FN. FB and FN were measured at various degrees of knee flexion. The triangular area within the borders of FB, FN and the path

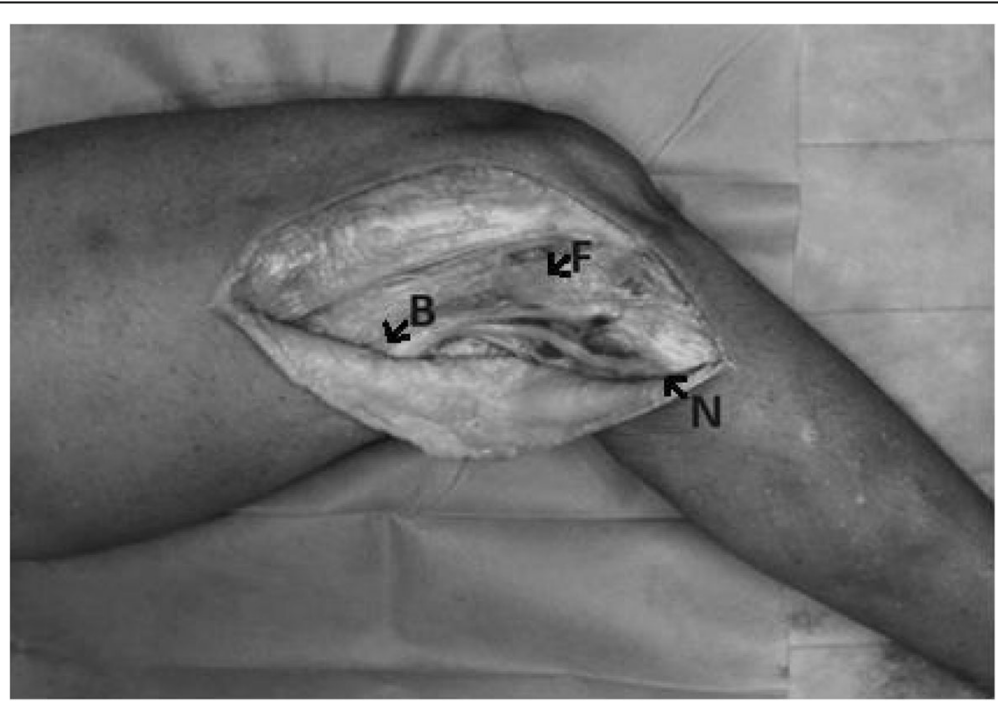

Figure. 1 Picture of a specimen showing the incision, exposed area and points F, B and N 
of the CPN was calculated using Heron's formula [6]. For two specimens, area FBN could not be calculated hence these two specimens were excluded during analysis for area FBN. For these two specimens, area FBN could not be calculated as the knee was placed at $0^{\circ}$ of flexion (in full extension) and the three points $\mathrm{F}, \mathrm{B}$ and $\mathrm{N}$ were collinear.

The measurements were further replicated with the knee placed in $0,30,60$ and $120^{\circ}$ of flexion. An electronic goniometer was attached to the specimen to confirm the flexion angle of the specimen.

After tabulation of results, data analysis was performed using SPSS 20.0 statistical software. The means of distances $\mathrm{FN}$ and $\mathrm{FB}$, length $\mathrm{BN}$ and area $\mathrm{FBN}$ were compared using one-way analysis of variance (ANOVA) tests. Post-hoc tests were performed using Tukey's Honestly Significant Difference (HSD) test. A $p$ value of $<$ 0.05 was considered significant.

\section{Results}

The CPN was identified in all 12 specimens. Mean measurements at varying angles of the various distances between the tip of the fibular head $(\mathrm{F})$, the posterior border of the fibular neck where the CPN crosses $(\mathrm{N})$ and the posterior border of the biceps femoris where the CPN crosses (B) are provided in Table 2. Post-hoc analysis of mean difference between subgroups is provided in Table 3 .

\section{Distance FN}

The distance FN between the tip of the fibular head and the posterior border of the fibular neck where the CPN crosses showed minimal change despite varying degrees of knee flexion from 0 to $120^{\circ}$. The mean value of distance FN was $20.7 \mathrm{~mm}$ (95\% CI 19.7-21.7). The distance was longest at $60^{\circ}$ of knee flexion where it was $22.7 \mathrm{~mm}$. However, there was no difference between means of FN $(p=0.131)$ at varying degrees of knee flexion.

\section{Distance FB}

The distance FB between tip of the fibular head and the posterior border of the biceps femoris where the CPN crosses showed an initial increase from up to $30^{\circ}$, at $62.34 \mathrm{~mm}$, before it subsequently decreased with further knee flexion. The mean value of distance FB was 53.1 $\mathrm{mm}$ and it was statistically different at varying degrees of knee flexion $(p<0.001)$. Post-hoc analysis revealed significant differences in means between $0-120^{\circ}(p=0.004)$, $30-120^{\circ}(p<0.001)$ and $60-120^{\circ}(p=0.002)$.

\section{Distance BN}

The length $\mathrm{BN}$ of the peroneal nerve between the two fixed points $\mathrm{B}$ and $\mathrm{N}$ was greatest at $76.1 \mathrm{~mm}$ at $30^{\circ}$ of flexion. The mean value of length $\mathrm{BN}$ was $60.4 \mathrm{~mm}$, and this was also statistically different at varying degrees of knee flexion $(p<0.001)$. Post-hoc analysis revealed
Table 2 Findings of various distances from the tip of the fibular head $(F)$, to the posterior border of the biceps femoris where the peroneal nerve crosses (B) and the posterior border of the fibular neck where the peroneal nerve crosses $(\mathrm{N})$, and the area of the triangle FBN

\begin{tabular}{|c|c|c|c|}
\hline & Degrees of knee flexion & No. & Mean $(95 \% \mathrm{CI})$ \\
\hline \multirow[t]{6}{*}{ Distance FN (mm) } & 0 & 12 & $19.8(17.5-22.2)$ \\
\hline & 30 & 12 & $21.7(19.3-24.1)$ \\
\hline & 60 & 12 & $22.7(20.0-25.4)$ \\
\hline & 90 & 12 & $20.1(18.3-21.8)$ \\
\hline & 120 & 12 & $19.3(17.0-21.5)$ \\
\hline & - & 60 & $20.7(19.7-21.7)$ \\
\hline \multirow[t]{6}{*}{ Distance FB (mm) } & 0 & 12 & $57.9(48.0-67.9)$ \\
\hline & 30 & 12 & $62.3(55.0-69.7)$ \\
\hline & 60 & 12 & $59.5(49.6-69.4)$ \\
\hline & 90 & 12 & $48.1(40.5-55.7)$ \\
\hline & 120 & 12 & $37.8(31.0-44.7)$ \\
\hline & - & 60 & $53.1(49.1-57.2)$ \\
\hline \multirow[t]{6}{*}{ Distance BN (mm) } & 0 & 12 & $72.8(61.6-84.0)$ \\
\hline & 30 & 12 & $76.1(67.9-84.4)$ \\
\hline & 60 & 12 & $69.2(59.8-78.49)$ \\
\hline & 90 & 12 & $52.2(46.0-58.5)$ \\
\hline & 120 & 12 & $31.8(27.2-36.4)$ \\
\hline & - & 60 & $60.4(55.1-65.8)$ \\
\hline \multirow[t]{6}{*}{ Area FBN $\left(\mathrm{mm}^{2}\right)$} & 0 & 10 & $423.5(252.9-594.1)$ \\
\hline & 30 & 12 & $530.5(407.1-653.8)$ \\
\hline & 60 & 12 & $621.2(468.4-774.1)$ \\
\hline & 90 & 12 & $466.6(362.3-570.8)$ \\
\hline & 120 & 12 & $296.3(229.8-362.8)$ \\
\hline & - & 58 & $469.1(412.1-526.2)$ \\
\hline
\end{tabular}

significant differences in means amongst almost all groups, except between $0-30^{\circ}, 0-60^{\circ}$ and $30-60^{\circ}$.

\section{Area FBN}

The triangular area FBN was largest at $60^{\circ}$ of knee flexion at $621.2 \mathrm{~mm}^{2}$, respectively. The space decreased with further increasing angles of knee flexion. The mean value of area FBN was $469.1 \mathrm{~mm}^{2}$ (95\% CI 412.1-526.2) and this was statistically different at varying degrees of knee flexion $(p=0.003)$. Post-hoc analysis revealed significant differences in means between $30-120^{\circ}(p=$ $0.035)$ and $60-120^{\circ}(p=0.001)$.

\section{Discussion}

An injury to the CPN potentially results in significant morbidity such as a permanent foot drop, which can occur in up to $2.5 \%$ of cases [1]. A clear and precise reference is important to the surgeon during surgery at the PLC, to reduce risks of iatrogenic damage. This is 
Table 3 Post-hoc Tukey's Honestly Significant Difference (HSD) for distances FN, FB, BN and area FBN (n.s. = not significant)

\begin{tabular}{|c|c|c|c|c|c|c|c|c|}
\hline \multirow{2}{*}{$\begin{array}{l}\text { Difference } \\
\text { in groups }\end{array}$} & \multicolumn{2}{|l|}{ Distance FN (mm) } & \multicolumn{2}{|l|}{ Distance FB (mm) } & \multicolumn{2}{|l|}{ Distance BN (mm) } & \multicolumn{2}{|l|}{ Area FBN $\left(\mathrm{mm}^{2}\right)$} \\
\hline & $\begin{array}{l}\text { Mean difference } \\
(95 \% \mathrm{Cl})\end{array}$ & $\overline{p \text { value }}$ & $\begin{array}{l}\text { Mean difference } \\
(95 \% \mathrm{Cl})\end{array}$ & $\overline{p \text { value }}$ & $\begin{array}{l}\text { Mean difference } \\
(95 \% \mathrm{Cl})\end{array}$ & $\overline{p \text { value }}$ & $\begin{array}{l}\text { Mean difference } \\
(95 \% \mathrm{Cl})\end{array}$ & $p$ value \\
\hline $0-30$ & $-1.84(-6.02-2.34)$ & n.s. & $-4.42(-19.71-10.88)$ & n.s. & $-3.33(-18.29-11.63)$ & n.s. & $-107.00(-340.69-126.70)$ & n.s. \\
\hline $0-60$ & $-2.85(-7.03-1.33)$ & n.s. & $-1.57(-16.86-13.73)$ & n.s. & $3.65(-11.31-18.61)$ & n.s. & $-197.75(-431.45-35.95)$ & n.s. \\
\hline $0-90$ & $-0.21(-4.39-3.97)$ & n.s. & $9.85(-5.44-25.14)$ & n.s. & $20.57(5.61-35.53)$ & $<0.001$ & $-43.12(-276.81-190.59)$ & n.s. \\
\hline $0-120$ & $0.58(-3.60-4.76)$ & n.s. & $20.09(4.80-35.38)$ & 0.004 & 40.98 (26.02-55.93) & $<0.001$ & $127.18(-106.52-360.88)$ & n.s. \\
\hline $30-60$ & $-1.01(-5.19-3.17)$ & n.s. & $2.85(-12.44-18.14)$ & n.s. & $6.98(-7.98-21.94)$ & n.s. & $-90.75(-313.58-132.07)$ & n.s. \\
\hline $30-90$ & $1.63(-2.55-5.81)$ & n.s. & $14.27(-1.03-29.56)$ & n.s. & $23.90(8.94-38.86)$ & $<0.001$ & $63.89(-158.94-286.71)$ & n.s. \\
\hline $30-120$ & $2.43(-1.76-6.61)$ & n.s. & $24.51(9.22-39.80)$ & $<0.001$ & $44.31(29.35-59.27)$ & $<0.001$ & $234.18(11.36-457.00)$ & 0.035 \\
\hline $60-90$ & $2.64(-1.54-6.82)$ & n.s. & $11.42(-3.87-26.71)$ & n.s. & $16.92(1.96-31.88)$ & 0.019 & $154.64(-68.18-377.46)$ & n.s. \\
\hline $60-120$ & $3.43(-0.75-7.61)$ & n.s. & $21.66(6.37-36.95)$ & 0.002 & $37.33(22.37-52.28)$ & $<0.001$ & $324.93(102.11-547.76)$ & 0.001 \\
\hline $90-120$ & $0.79(-3.39-4.97)$ & n.s. & $10.24(-5.05-25.53)$ & n.s. & $20.41(5.45-35.37)$ & 0.003 & $170.29(-52.53-393.12)$ & n.s. \\
\hline
\end{tabular}

especially so if there is altered anatomy at the PLC that may make identification of the CPN even more challenging.

This study found that the mean position of the CPN at the PLC with respect to the tip of the fibular head was at $53.1 \pm 4.1 \mathrm{~mm}$ on the biceps femoris and $20.7 \pm 1 \mathrm{~mm}$ on the fibular neck. Hildebrand reported a value of $21.9 \pm 1.8 \mathrm{~mm}$ from the tip of the fibular styloid to the posterior border of the fibula [7]. Of note, there was no difference in mean value with change in degree of knee flexion for position on the fibular neck $(p=0.131)$, indicating that the exit point of the CPN at the PLC could be more consistently identified regardless of knee position. Surgeons who are not familiar with this region may opt to first locate the CPN on the fibular neck and trace its course proximally given a typical anatomy with approximately $81 \%$ of the cases having division of the CPN into its deep and superficial branches at, or distal to, the fibular neck [8]. These are objective distances from the fibular head, which is a fixed reference point except in certain cases such as displaced fibular-head fractures, or proximal tibiofibular joint dislocations. These distances enable the identification and protection of the nerve during surgery and mobilisation of the nerve should the need arise. This potentially reduces the risk of nerve injury intra-operatively.

Both Hildebrand and Thi reported similar distances between the fibular head and the CPN as it enters the PLC at the biceps femoris at varying angles of knee flexion $[7,9]$. However, this study did not concur, and also found that the value of distance FB is variable depending on degree of knee flexion $(p<0.001)$. As such, it is difficult to predict the entry point of the CPN into the PLC. This correlates with the more mobile attachment where the nerve crosses the posterior border of the biceps femoris, compared to the lesser mobile point at which the nerve penetrates the fascia to continue its course in the peroneal compartment. Mobility of the $\mathrm{CPN}$ can be improved by proximal and distal release of more importance is the distal entry into the peroneal compartment. A fascial release at the distal entry point into the peroneal compartment during surgery would prevent unnecessary tension on the nerve during the surgery, and potentially reduce post-surgical neuropraxia due to compromise of the intrafascicular microcirculation [10].

The area demarcated by these landmarks is the working space available during surgery, and is dependent on the degree of knee flexion $(p=0.003)$. It is dynamically adjusted during surgery by positioning the knee according to the exposure required at a particular stage in surgery. It was largest at 30 and $60^{\circ}$ of flexion, which indicates that the peroneal nerve is likely under the greatest tension in those positions. This is based on the assumption that tension is proportionately correlated with distance between the two fixed points. Thus, it is assumed that the tension on the nerve is proportionately increased when the knee is moved to 60 and $30^{\circ}$, respectively. Since surgery at the PLC is often performed at $90^{\circ}$ of flexion, the CPN is not maximally stretched and, hence, risk of neuropraxia arising due to tension is not increased. Should more space and exposure be required during surgery, the angle of knee flexion could be reduced from $90^{\circ}$ to $60^{\circ}$ in order to optimise the area available. However, caution should still be applied when handling the CPN under greater tension in these positions as there is risk of nerve injury when intending to improve its exposure at the PLC.

\section{Limitations}

There are several limitations in this study.

Firstly, the CPN is not completely immobile at where it crosses the posterior border of the biceps femoris, with attachments to it by the interstitial tissue. This 
could possibly have resulted in a lower value of $\mathrm{FB}$ as the nerve, with its elasticity and tensile strength (albeit limited), could be tauter during changes in knee angles from extension to $90^{\circ}$ of flexion. Secondly, the study is an attempt, using two-dimensional (2D) measurement, to demarcate a three-dimensional (3D) zone. This could potentially be overcome by the use of non-contact measurement systems, otherwise known as photogrammetry, to capture multiple $2 \mathrm{D}$ images and reverse-engineer the 3D measurements from captured images [11]. Thirdly, the accuracy of the results was limited by the number of cadaveric knee specimens available. However, it should be noted that despite wide variations in anthropometric measurements of specimens that may not be representative of the normal population, there was normal variance noted for measurements FN, FB and BN. Lastly, the measurements used in this study and other literature are usually to a tenth of a millimeter, but this may be different in actual surgery as considerations must be taken in context to the patients' size and individual anatomy. However, this study has likely obtained a close estimate to serve the purpose of aiding navigation for a surgeon.

\section{Conclusions}

A reproducible reference to a relatively consistent landmark facilitates the identification of the CPN during surgery at the PLC. These measurements are potentially useful for a surgeon who is not familiar with this region. The study also showed that the routine working position of $90^{\circ}$ of flexion also ensures that the CPN is not subjected to tension and an inadvertent increased risk of neuropraxia.

\begin{abstract}
Abbreviations
BN: Common peroneal nerve from entry to exit point of posterolateral corner; CPN: Common peroneal nerve; FB: Tip of fibular head to the point where the common peroneal nerve crosses the posterior border of biceps femoris; FN: Tip of fibular head to the point where the common peroneal nerve enters the fascia at the level of the fibular neck; FBN: Triangular area within the borders of $\mathrm{FB}, \mathrm{FN}$ and the path of the common peroneal nerve; PLC: Posterolateral corner; 2D: Two-dimensional; 3D: Three-dimensional
\end{abstract}

\section{Acknowledgements}

Not applicable

\section{Authors' contributions}

TTHL performed cadaveric dissection and measurements. All authors analysed and interpreted the data. MAKX was a major contributor in writing the manuscript. All authors read and approved the final manuscript.

\section{Authors' information}

Not applicable

\section{Funding}

This work was supported by the Changi General Hospital Research Grant (Number 12200257).

\section{Availability of data and materials}

The datasets during and/or analysed during the current study are available from the corresponding author on reasonable request.
Ethics approval and consent to participate

Not applicable

\section{Consent for publication}

Not applicable

\section{Competing interests}

The authors declare that they have no competing interests.

Received: 9 August 2019 Accepted: 7 April 2020

Published online: 24 May 2020

References

1. Deutsch A, Wyzykowski RJ, Victoroff BN (1999) Evaluation of the anatomy of the common peroneal nerve. Defining nerve-at-risk in arthroscopically assisted lateral meniscus repair. Am J Sports Med 27(1):10-15

2. LaPrade RF, Terry GC (1997) Injuries to the posterolateral aspect of the knee: association of anatomic injury patterns with clinical instability. Am J Sports Med 25:433-438 Accessed 10 Dec 2019

3. Kennedy JC (1963) Complete dislocation of the knee joint. J Bone Joint Surg Am 45:889-904

4. Shields L, Mital M, Cave EF (1969) Complete dislocation of the knee: experience at the Massachusetts General Hospital. J Trauma 9(3):192-215

5. Girolami M, Galletti S, Montanari G, Mignani G, Schuh R, Ellis S, Di Motta D, D'Apote G, Bevoni R (2013) Common peroneal nerve palsy due to hematoma at the fibular neck. J Knee Surg 26(Suppl 1):S132-S135

6. Proof of Heron's Formula. http://galileoandeinstein.physics.virginia.edu/ more_stuff/Heron.html. Accessed 20 Nov 2019

7. Hildebrand G, Tompkins M, Macalena J (2015) Fibular head as a landmark for identification of the common peroneal nerve: a cadaveric study. Arthrosc J Arthrosc Relat Surg 31:99-103 Accessed 20 Nov 2019

8. Krivic A, Stanec S, Zic R, Budi S, Milanovic R, Stanec Z (2003) Lesion of the common peroneal nerve during arthroscopy. Arthroscopy. 19(9):1015-1018 Accessed 10 May 2018

9. Thi C, Van Huy N, Nguyen NC, Thanh TH (2018) Applied anatomy of common peroneal nerve: a cadaveric study. Int J Med 6(1):6-10

10. Sunderland S (1990) The anatomy and physiology of nerve injury. Muscle Nerve 13:771-784

11. Rausch V, Hackl M, Oppermann J, Leschinger T, Scaal M, Müller LP, Wegmann K (2019) Peroneal nerve location at the fibular head: an anatomic study using 3D imaging. Arch Orthop Trauma Surg 139(7):921-926

\section{Publisher's Note}

Springer Nature remains neutral with regard to jurisdictional claims in published maps and institutional affiliations.
Ready to submit your research? Choose BMC and benefit from:
- fast, convenient online submission
- thorough peer review by experienced researchers in your field
- rapid publication on acceptance
- support for research data, including large and complex data types
- gold Open Access which fosters wider collaboration and increased citations
- maximum visibility for your research: over $100 \mathrm{M}$ website views per year
At BMC, research is always in progress.
Learn more biomedcentral.com/submissions 